\title{
Clinical outcomes of adverse cardiovascular events in patients with acute dapsone poisoning
}

\author{
Kyung Sik Kang, Hyung II Kim, Oh Hyun Kim, Kyoung Chul Cha, \\ Hyun Kim, Kang Hyun Lee, Sung Oh Hwang, Yong Sung Cha \\ Department of Emergency Medicine, Yonsei University Wonju College of Medicine, Wonju, Korea
}

Objective Adverse cardiovascular events (ACVEs) account for a large proportion of the morbidities and mortalities associated with drug overdose emergencies. However, there are no published reports regarding outcomes of ACVEs associated with acute dapsone poisoning. Here, the authors retrospectively analyzed ACVEs reported within 48 hours of treatment in patients with acute dapsone poisoning and assessed the significance of ACVEs as early predictors of mortality.

Methods Sixty-one consecutive cases of acute dapsone poisoning that were diagnosed and treated at a regional emergency center between 2006 and 2014 were included in the study. An ACVE was defined as myocardial injury, shock, ventricular dysrhythmia, cardiac arrest, or any combination of these occurring within the first 48 hours of treatment for acute dapsone poisoning.

Results Nineteen patients (31.1\%) had evidence of myocardial injury (elevation of serum troponin-I level or electrocardiography signs of ischemia) after dapsone overdose, and there were a total of 19 ACVEs (31.1\%), including one case of shock (1.6\%). Fourteen patients (23.0\%) died from pneumonia or multiple organ failure, and the incidence of ACVEs was significantly higher among non-survivors than among survivors (64.3\% vs. $21.3 \%, P=0.006)$. ACVE was a significant predictor of mortality (odds ratio, 5.690; 95\% confidence interval, 1.428 to $22.675 ; \mathrm{P}=0.014$ ).

Conclusion The incidence of ACVE was significantly higher among patients who died after acute dapsone poisoning. ACVE is a significant predictor of mortality after dapsone overdose, and evidence of ACVE should be carefully sought in these patients.

Keywords Dapsone; Intoxication; Cardiac injury; Troponin I; Mortality

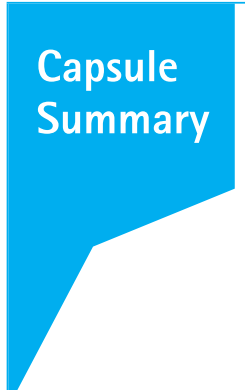

What is already known

Adverse cardiovascular events (ACVEs) account for a large proportion of deaths related to acute drug overdose. However, the implications of ACVE after acute dapsone poisoning are not well known.

What is new in the current study

ACVE occurred in 19 of 61 patients (31.1\%) during the first 48 hours after acute overdose. Early ACVE was a significant predictor of mortality.
elSSN: 2383-4625

Received: 6 October 2015

Revised: 26 October 2015

Accepted: 19 December 2015

Correspondence to: Yong Sung Cha Department of Emergency Medicine, Yonsei University Wonju College of Medicine, 20 Ilsan-ro, Wonju 26426, Korea

E-mail: zza96@hanmail.net

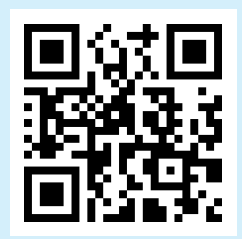

How to cite this article:

Kang KS, Kim HI, Kim OH, Cha KC, Kim H, Lee KH, Hwang SO, Cha YS. Clinical outcomes of adverse cardiovascular events in patients with acute dapsone poisoning. Clin Exp Emerg Med 2016;3(1):41-45.

This is an Open Access article distributed under the terms of the Creative Commons Attribution Non-Commercial License (http:// creativecommons.org/licenses/by-nc/3.0/). 


\section{INTRODUCTION}

Dapsone is a bacteriostatic sulfone antibiotic that has been used as a major component in multidrug treatment of leprosy since the 1940s. ${ }^{12}$ The adverse effects of dapsone at therapeutic doses include neutropenia, thrombocytopenia, eosinophilic pneumonia, aplastic anemia, hemolysis, neuropathy, hepatitis, and agranulocytosis, and acute adverse effects include, nausea, vomiting, abdominal pain, methemoglobinemia, seizure, and coma. ${ }^{3.4}$ Hypersensitivity myocarditis has also been associated with dapsone at therapeutic doses. ${ }^{5-8}$

Adverse cardiovascular events (ACVEs) account for a substantial proportion of the morbidity and mortality associated with drug overdose emergencies, ${ }^{9}$ but little is known of the implications of ACVEs arising as a result of acute dapsone overdose, specifically ACVEs that are identified by elevated troponin levels.

New cases of leprosy are rare at Wonju Severance Christian Hospital, but dapsone use is still relatively common in our area (Wonju, Korea) because there was a leper colony nearby during the 1960s and 1970s. Dapsone poisoning is known to have a high mortality rate. ${ }^{10}$ We wanted to determine the frequency and nature of ACVEs associated with dapsone poisoning, and to examine the relationship between ACVEs and mortality in cases of acute dapsone poisoning.

Accordingly, we determined the incidence of ACVE within 48 hours of the start of treatment and compared general characteristics, including ACVE, in survivors and non-survivors; based on this, we evaluated the significance of ACVE as an early predictor of mortality in cases of acute dapsone poisoning.

\section{METHODS}

\section{Study design and data collection}

This was a retrospective observational study that included consecutive patients diagnosed with acute dapsone poisoning at a regional emergency center between January 2006 and June 2014. Serum high sensitivity troponin I levels (hs-Tnl; Siemens Healthcare Diagnostics, Newark, DE, USA; normal range $<0.046 \mathrm{ng} / \mathrm{mL}$ ) were measured in all included patients. Dapsone ingestion was confirmed by patients or guardians, and dapsone toxicity was confirmed by the treating emergency physician and verified by serum methemoglobin levels. The study exclusion criteria were age $<18$ years, end-stage renal disease, and the absence of serum $\mathrm{Tnl}$ measurement during the first 48 hours after arrival at the emergency department.

The following data were obtained from the medical records of the included patients: age, gender, amount ingested, underlying disease, initial symptoms and signs, initial Glasgow Coma Scale (GCS) score, initial systolic blood pressure, and treatment, including methylene blue, gastric irrigation, activated charcoal, and multidose activated charcoal. Electrocardiograms, when available, were reviewed by an experienced cardiologist (HSO) and ventricular dysrhythmias and signs of ischemic change were noted. Serum methemoglobin, hs-Tnl, and beta-type natriuretic peptide levels at the time of initial presentation were also recorded. Data collection was conducted by two emergency physicians who were blinded to the study objectives and hypothesis. Both underwent training before data collection to reduce bias by disagreement.

ACVE was defined by at least one of the following: 1) myocardial injury as evidenced by hs-Tnl elevation within 48 hours of presentation or electrocardiography (ECG) signs of ischemia including ST elevation, ST depression, or T wave inversion; 2) shock, as defined by hypotension requiring vasopressor support; 3) ventricular dysrhythmia, including ventricular tachycardia, ventricular fibrillation, or torsades des pointes; and 4) cardiac arrest..11-16 We included only ACVEs that were apparent during the first 48 hours because we wanted to identify early predictors of mortality and minimize the possibility that an ACVE was secondary to malfunction of other organs or systems or multiple organ failure in the terminal stage.

General characteristics of each case of acute dapsone poisoning, including mortality and the incidence of ACVE, were assessed, and we compared characteristics of survivors and non-survivors to examine the relationship between ACVEs and mortality. This study was approved by the institutional review board of Wonju College of Medicine, Yonsei University.

\section{Statistical analyses}

Statistical analyses were performed using IBM SPSS Statistics ver. 20 (IBM, Armark, NY, USA). Categorical variables were presented as frequencies and percentages, and continuous variables as medians and interquartile ranges after assessment for normality using the Shapiro-Wilk test. The chi-square test or Fisher's exact test was used to compare categorical variables and the MannWhitney U-test was used to compare continuous variables. Predictors of mortality were identified by multiple logistic regression analysis. P-values of $<0.05$ were considered statistically significant.

\section{RESULTS}

Characteristics of patients with acute dapsone poisoning Among 74 consecutive patients who had acute dapsone poisoning during the study period, 61 patients (16 men [26.2\%], age 18 
to 91 years, median 67 years) were included in this retrospective study and 13 were excluded (five who were $<18$ years old, one with end stage renal disease, and seven who did not have serum hs-Tnl measurements within 48 hours of arrival).

The amount of dapsone ingested varied from $300 \mathrm{mg}(3 \times 100$ $\mathrm{mg}$ tablets) to $3 \mathrm{~g}$ (30 $\times 100 \mathrm{mg}$ tablets). The pills were ingested intentionally in all cases. Hypertension was the most common cardiovascular risk factor. Common signs and symptoms at initial presentation were cyanosis (40 patients, 65.6\%), dyspnea (30 patients, 49.2\%), and headache (8 patients, 13.1\%). Other symptoms included nausea, vomiting, general weakness, dizziness, and seizures (Table 1).

ACVE in the form of myocardial injury occurred in 19 patients (31.1\%); among them, 12 (19.7\%) had elevated hs-Tnl and 10 (16.4\%) had ECG changes (4 with ST depression and 6 with T wave inversion); shock was reported in one patient in this group (1.6\%). No cases of ventricular dysrhythmia or cardiac arrest were noted.

Table 1. General and laboratory characteristics of patients with acute dapsone poisoning

\begin{tabular}{lc}
\hline Characteristics & Value $(\mathrm{n}=61)$ \\
\hline Age (yr) & $67(51-79)$ \\
Male sex & $16(26.2)$ \\
Ingestion dose (mg) & $500(375-1,375)$ \\
Time from ingestion to ED arrival (hr) & $10.0(3.0-13.9)$ \\
Underlying disease & \\
Diabetes mellitus & $16(26.2)$ \\
Hypertension & $32(52.5)$ \\
Hyperlipidemia & $1(1.6)$ \\
Initial symptoms and signs & \\
Cyanosis & $40(65.6)$ \\
Dyspnea & $30(49.2)$ \\
Headache & $8(13.1)$ \\
Initial Glasgow Coma Scale & $15(12-15)$ \\
Systolic blood pressure (mmHg) & $136(120-152)$ \\
Initial methemoglobin $(\%)$ & $34.6(27.0-40.0)$ \\
Initial high sensitivity Tnl $(\mathrm{ng} / \mathrm{mL})$ & $0.015(0.007-0.030)$ \\
$\beta$-natriuretic peptide (pg/mL) & $56.83(14.66-88.55)$ \\
Use of methylene blue & $59(96.7)$ \\
Gastric irrigation & $24(39.3)$ \\
Activated charcoal & $39(63.9)$ \\
Multidose activated charcoal & $9(14.8)$ \\
Adverse cardiovascular events & $19(31.1)$ \\
Myocardial injury & $19(31.1)$ \\
Elevation of Tnl & $12(19.7)$ \\
$\quad$ Ischemic change of ECG & $10(16.4)$ \\
Shock & $1(1.6)$ \\
Ventricular dysrhythmia & $0(0)$ \\
Cardiac arrest & $0(0)$ \\
Mortality & $14(23.0)$ \\
\hline & \\
\hline
\end{tabular}

Values are presented as median (interquartile range) or number (\%). $E D$, emergency department; Tnl, troponin I; ECG, electrocardiography.
Median initial hs-Tnl and beta-type natriuretic peptide levels were $0.015 \mathrm{ng} / \mathrm{mL}$ and $56.83 \mathrm{pg} / \mathrm{mL}$, respectively. Regarding treatment, 59 patients (96.7\%) received methylene blue and nine (14.8\%) received multidose activated charcoal. Fourteen of the 61 patients (23.0\%) ultimately died from pneumonia or multiple organ failure (Table 1).

\section{Comparison of survivors and non-survivors}

There were 14 non-survivors and 47 survivors (77.0\%). As a group, the non-survivors were older than the survivors (median age 80 vs. 64 years, $P=0.005$ ) and had significantly lower GCS scores at arrival. The rate of ACVE was significantly higher among the nonsurvivors (64.3\% vs. $21.3 \%, P=0.006)$. Finally, there was a significant difference in median total dose of methylene blue between non-survivors and survivors (2,425 vs. 800 mg, $P=0.004)$ (Table 2).

Multiple logistic regression analysis showed that among age, initial GCS score, and presence of ACVE, only ACVE (odds ratio, 5.690; 95\% confidence interval, 1.428 to $22.675 ; P=0.014$ ) was significantly associated with mortality (Table 3 ).

\section{DISCUSSION}

There was a greater incidence of ACVE development within the first 48 hours of treatment for dapsone poisoning than we anticipated, and the rate of early ACVE was significantly higher in nonsurvivors than in survivors (Table 2). Logistic regression analysis confirmed a significant association between early cardiac injury and mortality, and ours is the first study to report this finding in relation to acute dapsone poisoning. Evaluation for early signs of ACVE, such as serum hs-Tnl levels $>0.046 \mathrm{ng} / \mathrm{mL}$ or ECG changes characteristic of ischemia, should be a part of the initial prognostic workup for patients with acute dapsone poisoning.

Tnl is useful for detecting acute myocardial injury because it is expressed as a cardiac-specific isoform. ${ }^{17}$ Experimental data strongly suggest that Tnl leaks from cells only after membrane disruption following myocardial cell death. ${ }^{18}$ High-sensitivity troponin assays permit early detection of circulating $\mathrm{Tnl}$ resulting from transient ischemia or inflammatory myocardial injury..$^{19}$ In the present study, all of the patients who had early ACVE after dapsone overdose had myocardial injury. Only three of 12 patients with elevated serum hs-Tnl levels had ECG changes consistent with ischemia. Therefore, we suggest that both ECG and serum Tnl level should be used to check for myocardial injury in patients with acute dapsone poisoning.

Two mechanisms of cardiotoxicity related to dapsone-induced ACVE have been proposed. First, methemoglobinemia may lead to myocardial cell death because of reduced oxygen delivery to the 
Table 2. Comparison of survivors and non-survivors

\begin{tabular}{|c|c|c|c|}
\hline Characteristic & Survivors $(n=47,77.0 \%)$ & Non-survivors $(n=14,23.0 \%)$ & P-value \\
\hline Age (yr) & $64(51-78)$ & $80(68-83)$ & 0.005 \\
\hline Male sex & $14(29.8)$ & $2(14.3)$ & 0.318 \\
\hline Ingestion dose (mg) & $500(288-1,375)$ & $875(425-2,188)$ & 0.503 \\
\hline \multicolumn{4}{|l|}{ Underlying disease } \\
\hline Diabetes mellitus & $11(23.4)$ & $5(35.7)$ & 0.490 \\
\hline Hypertension & $24(51.1)$ & $8(57.1)$ & 0.689 \\
\hline Hyperlipidemia & $1(2.1)$ & $0(0)$ & 1.000 \\
\hline \multicolumn{4}{|l|}{ Initial symptoms and signs } \\
\hline Cyanosis & $28(59.6)$ & 12 (85.7) & 0.109 \\
\hline Dyspnea & $23(48.9)$ & $7(50.0)$ & 0.944 \\
\hline Headache & $8(17.0)$ & $0(0)$ & 0.180 \\
\hline Initial Glasgow Coma Scale & $15(13-15)$ & $13(9-14)$ & 0.009 \\
\hline Systolic blood pressure $(\mathrm{mmHg})$ & $135(120-150)$ & $138(130-166)$ & 0.274 \\
\hline Initial methemoglobin (\%) & $33.6(23.1-39.7)$ & $37.8(31.6-40.9)$ & 0.162 \\
\hline Initial hs-Tnl (ng/mL) & $0.014(0.006-0.015)$ & $0.039(0.013-0.556)$ & 0.007 \\
\hline$\beta$-natriuretic peptide $(\mathrm{pg} / \mathrm{mL})$ & 36.24 (12.29-88.52) & $63.48(54.32-147.12)$ & 0.138 \\
\hline Use of methylene blue & 45 (95.7) & $14(100)$ & 1.000 \\
\hline Total dose of methylene blue $(\mathrm{mg})$ & $800(450-1,500)$ & $2,425(1,285-3,840)$ & 0.004 \\
\hline Gastric irrigation & $18(38.3)$ & $6(42.9)$ & 0.759 \\
\hline Activated charcoal & $32(68.1)$ & $7(50.0)$ & 0.216 \\
\hline Multidose activated charcoal & $7(14.9)$ & $2(14.3)$ & 1.000 \\
\hline Adverse cardiovascular events & $10(21.3)$ & $9(64.3)$ & 0.006 \\
\hline
\end{tabular}

Values are presented as median (interquartile range) or number (\%).

hs-Tnl, high sensitivity troponin I.

Table 3. Early predictors of mortality

\begin{tabular}{lccc}
\hline & Odds ratio & $\begin{array}{c}95 \% \text { confidence } \\
\text { interval }\end{array}$ & P-value \\
\hline Age & 1.030 & $0.979-1.083$ & 0.256 \\
Adverse cardiovascular events & 5.690 & $1.428-22.675$ & 0.014 \\
Glasgow Coma Scale & 0.876 & $0.712-1.078$ & 0.212 \\
\hline
\end{tabular}

cells. Second, reduced intravascular volume, vascular resistance, or myocardial contractility due to myocardial stunning may lead to cardiogenic shock. ${ }^{20}$

Only one patient in our study population developed shock requiring vasopressor support during the first 48 hours of treatment, and there were no cases of ventricular dysrhythmia or cardiac arrest.

We did not include cases of shock and cardiac arrest associated with multiple organ failure during the late period in our analysis because we wanted to identify early predictors of mortality. Our comparison of non-survivors and survivors showed that median age, median initial GCS score, total dose of methylene blue, and incidence of ACVE differed significantly between these two groups. We attributed the finding that non-survivors were older than survivors to weaker physiologic defense mechanisms among the older patients, and we also attributed the lower GCS scores and higher rate of ACVEs among non-survivors to this age difference. We speculated that the differences in total dose of methy- lene blue were related to the persistence of methemoglobinemia in non-survivors compared to survivors.

This study has some limitations that bear consideration. First, it was conducted using a retrospective design at a single hospital, and as a result, not all relevant assessment parameters were included, especially initial symptoms and past history. Serum betatype natriuretic peptide was checked in 36 (59.0\%) out of 61 patients, and echocardiography results as a measure of cardiac function in patients with $A C V E$, were not included in the analysis. Further studies are required to clarify these details. Nonetheless, our finding of a significant association between early indicators of ACVE and mortality in cases of acute dapsone poisoning should prompt physicians in the emergency department to consider checking serum biomarkers and ECG for early signs of ACVE in all patients who present with dapsone overdose.

The incidence of ACVE was significantly higher among patients who died after acute dapsone poisoning. ACVE is a significant predictor of mortality after dapsone overdose, and evidence of ACVE should be carefully sought in these patients.

\section{CONFLICT OF INTEREST}

No potential conflict of interest relevant to this article was reported. 


\section{REFERENCES}

1. Zhu YI, Stiller MJ. Dapsone and sulfones in dermatology: overview and update. J Am Acad Dermatol 2001;45:420-34.

2. Zuidema J, Hilbers-Modderman ES, Merkus FW. Clinical pharmacokinetics of dapsone. Clin Pharmacokinet 1986;11:299315.

3. Coleman MD. Dapsone-mediated agranulocytosis: risks, possible mechanisms and prevention. Toxicology 2001;162:5360.

4. Flomenbaum NE, Goldfrank LR, Hoffman RS, Howland MA, Lewin NA, Nelson LS. Goldfrank's toxicologic emergencies. New York: McGraw-Hill; 2006.

5. Lau G. A fatal case of drug-induced multi-organ damage in a patient with Hansen's disease: dapsone syndrome or rifampicin toxicity? Forensic Sci Int 1995;73:109-15.

6. Teo RY, Tay YK, Tan CH, Ng V, Oh DC. Presumed dapsone-induced drug hypersensitivity syndrome causing reversible hypersensitivity myocarditis and thyrotoxicosis. Ann Acad Med Singapore 2006;35:833-6.

7. Zhu KJ, He F, Jin N, Lou JX, Cheng H. Complete atrioventricular block associated with dapsone therapy: a rare complication of dapsone-induced hypersensitivity syndrome. J Clin Pharm Ther 2009;34:489-92.

8. Li, WH, Liu HN, Lee DD. Myocarditis in dapsone-induced drug reaction with eosinophilia and systemic symptoms: a case report and review of the literature. Dermatol $\operatorname{Sin} 2011 ; 29: 63-6$.

9. Bronstein AC, Spyker DA, Cantilena LR Jr, Green JL, Rumack BH, Giffin SL. 2009 Annual report of the American Association of Poison Control Centers' National Poison Data System (NPDS): 27th annual report. Clin Toxicol (Phila) 2010;48:9791178.

10. Park $\mathrm{KH}$, Kim H, Lee $\mathrm{CC}$, et al. Dapsone intoxication: clinical course and characteristics. Clin Toxicol (Phila) 2010;48:51621.
11. Albertson TE, Dawson A, de Latorre F, et al. TOX-ACLS: toxicologic-oriented advanced cardiac life support. Ann Emerg Med 2001;37(4 Suppl):S78-90.

12. Thygesen K, Alpert JS, White HD; Joint ESC/ACCF/AHA/WHF Task Force for the Redefinition of Myocardial Infarction. Universal definition of myocardial infarction. J Am Coll Cardiol 2007;50:2173-95.

13. Schoffstall JM, Spivey WH, Gambone LM, Shaw RP, Sit SP. Effects of calcium channel blocker overdose-induced toxicity in the conscious dog. Ann Emerg Med 1991;20:1104-8.

14. Patel AM, Singh JP, Ruskin JN. Role of implantable cardioverter-defibrillators in patients with methadone-induced long QT syndrome. Am J Cardiol 2008;101:209-11.

15. Boehnert MT, Lovejoy FH Jr. Value of the QRS duration versus the serum druglevel in predicting seizures and ventricular arrhythmias after an acute overdose of tricyclic antidepressants. N Engl J Med 1985;313:474-9.

16. Vanden Hoek TL, Morrison $\sqcup$, Shuster M, et al. Part 12: cardiac arrest in special situations: 2010 American Heart Association guidelines for cardiopulmonary resuscitation and emergency cardiovascular care. Circulation 2010;122(18 Suppl 3): S829-61.

17. Agewall $S$, Giannitsis $E_{1}$ Jernberg $T$, Katus H. Troponin elevation in coronary vs. non-coronary disease. Eur Heart J 2011; 32:404-11.

18. Fishbein MC, Wang T, Matijasevic M, Hong L, Apple FS. Myocardial tissue troponins T and I. An immunohistochemical study in experimental models of myocardial ischemia. Cardiovasc Pathol 2003;12:65-71.

19. Mingels AM, Jacobs LH, Kleijnen VW, et al. Cardiac troponin T elevations, using highly sensitive assay, in recreational running depend on running distance. Clin Res Cardiol 2010;99:385-91.

20. Manini AF, Nelson LS, Stimmel B, Vlahov D, Hoffman RS. Incidence of adverse cardiovascular events in adults following drug overdose. Acad Emerg Med 2012;19:843-9. 